\title{
Growth, seed development and genetic analysis in wild type and Def mutant of Pisum sativum L
}

\author{
Kwadwo Owusu Ayeh ${ }^{1}$, YeonKyeong Lee ${ }^{2}$, Mike J Ambrose ${ }^{3}$ and Anne Kathrine Hvoslef-Eide ${ }^{2^{*}}$
}

\begin{abstract}
Background: The def mutant pea (Pisum sativum L) showed non-abscission of seeds from the funicule. Here we present data on seed development and growth pattern and their relationship in predicting this particular trait in wild type and mutant lines as well as the inheritance pattern of the def allele in $F_{2}$ and $F_{3}$ populations.

Findings: Pod length and seed fresh weight increase with fruit maturity and this may affect the abscission event in pea seeds. However, the seed position in either the distal and proximal ends of the pod did not show any difference. The growth factors of seed fresh weight (FW), width of funicles (WFN), seed width (SW) and seed height $(\mathrm{SH})$ were highly correlated and their relationships were determined in both wild type and def mutant peas. The coefficient of determination $R^{2}$ values for the relationship between WFN and FW, SW and SH and their various interactions were higher for the def dwarf type. Stepwise multiple regression analysis showed that variation of WFN was associated with SH and SW. Pearson's chi square analysis revealed that the inheritance and segregation of the Def locus in 3:1 ratio was significant in two $F_{2}$ populations. Structural analysis of the F3 population was used to confirm the inheritance status of the Def locus in $F_{2}$ heterozygote plants.

Conclusions: This study investigated the inheritance of the presence or absence of the Def allele, controlling the presence of an abscission zone (AZ) or an abscission-less zone (ALZ) forming in wild type and mutant lines respectively. The single major gene (Def) controlling this phenotype was monogenic and def mutants were characterized and controlled by the homozygous recessive def allele that showed no palisade layers in the hilum region of the seed coat.
\end{abstract}

\section{Background}

A development funiculus (def) mutant pea (Pisum sativum) is known as a spontaneous mutation with monogenic recessive inheritance [1-4]. The chromosomal location of the Def allele has been found to be located at the bottom end of linkage group VII corresponding to chromosome no 4 [5-7]. Usually in wild type pea, there is a distinctive cell separation between funicle and seed coat that leads abscission of seed and results in detachment of seed from funicle. The wild type pea developed a double palisade layer and these may contribute to seed abscission [8]. In contrast, the palisade layers were absent in the def mutant pea and the funicle thus remained firmly attached to the seed coat resulting in non-abscission of seed from the pod. In spite of the distinct phenotypical differences between

\footnotetext{
* Correspondence: trine.hvoslef-eide@umb.no

2Department of Plant and Environmental Sciences, Norwegian University of Life Sciences, P.O. BOX 5003, 1432 Aas, Norway

Full list of author information is available at the end of the article
}

the wild type and def mutant, there was only limited information available on the trait $[5,9]$. In the present study, we differentiate seed growth and development in the wild type and the def mutant lines. The trait inheritance pattern in the Def locus was also examined in $\mathrm{F}_{2}$ and $\mathrm{F}_{3}$ segregate populations by crossing wild type (Def) and mutant (def).

In pea seeds, growth and development is characterized by three distinct phases and two lag phases [10]. The first phase comprises cell division of cotyledon cells. This phase is also described as pre-storage. The second phase is the maturation step and marks the period where cotyledon cells expand and proteins and starch are laid down as reserve compounds [11]. In the third phase, the maturation process is completed and the seed undergoes a desiccation period. The first lag period in seed growth correspond to a rapid decline in the growth of the testa and disappearance of the endosperm [12,13]. During the second lag phase, the level of the liquid endosperm declines to a minimum and the embryo then makes
Ciomed Central

(c) 2011 Ayeh et al.; licensee BioMed Central Ltd. This is an Open Access article distributed under the terms of the Creative Commons Attribution License (http://creativecommons.org/licenses/by/2.0), which permits unrestricted use, distribution, and reproduction in any medium, provided the original work is properly cited 
contact with the internal surface of the testa. The pattern of seed development is important in determining the optimum stage of seed maturation, that produces the maximum quantity and quality of seeds [14]. In plant species, the ovule may develop into a seed non-randomly with respect to ovule position in the ovary and there is a general tendency towards a greater probability of seed maturation at the distal end of the pod $[15,16]$. Therefore, it was useful to ascertain whether the effect of ovule position may have an effect on the developmental growth pattern in Def wild type and def mutant pea lines.

Allometric relationships are powerful predictive tools in plant sciences that may be used in predicting a particular a trait from other attributes of the plant [17]. Seed size has been found to be a useful attribute in predicting the ability of plants to establish in drought [18] and nutrient stress [19]. Seed size is an essential component of the life history in plants [20] because any small changes may cause differences in seedling growth, survival, and yield [21]. The funiculus is the only point of attachment between the developing seed and the plant. Nutrients are channelled from the pod via the funiculus to the seed coat [22]. Since the funiculus acts as a conduit through which nutrients pass from the plant into the seed, an allometric relationship between the funiculus and other seed attributes may provide valuable insights into its role in seed development.

In Mendelian genetics, the $F_{2}$ generation of a single monogenetic trait generally produce approximations to a 3:1 ratio depending on population size. However, deviations may occur with regards to the 3:1 ratio described as segregation distortion. Segregation distortion is the deviation of observed genetic ratios from the expected Mendelian ratios of a given genotypic class within a segregating population [23-25]. Lyttle [26], proposed that distorted segregation ratios may be the result from gametophytic competition where there is a preferred choice in fertilization, or the abortion of either the female or male gametes or zygotes. Taylor and Ingvarsson [27], has been specific in attributing the cause of segregation distortion to mechanisms that act in the male gametes. Segregation ratios that do not obey expected Mendelian ratios have been reported in a number of plants including pea (Pisum sativum) [28], common bean [29], mungbean (Vigna radiata L Wilcek) [30], barley (Hordeum vulgare) [31,32], maize (Zea mays) [33,34], rice (Oryza sativa) [35,36] and wheat (Triticum aestivum) [37-39]. Segregation analysis may serve as an important intermediate tool to help investigators plan more sophisticated genomic studies [40] and further enable breeders to manipulate major genes [41,42].

\section{Results}

\section{Pod length, seed position and seed fresh weight}

Pod length was measured to identify differences in growth patterns between Def wild type lines (JI 116 and
JI 2822) and def mutants (JI 1184 and JI 3020) (Tables ${ }^{\mathrm{Q}} 1$ and 2 ). The pod length in all four accessions increased as the pods matured although there was some variation among accessions. Pod length increased significantly at P3.1 and P5.1 in JI 116 and JI2822, respectively but wild type JI116 showed longer pods than def mutant JI 1184. The dwarf type increased significantly at P2.1 in both wild type JI2822 and JI3020 and dwarf mutant JI3020 showed longer pods than JI2822. Through observation and data, we established that pod length increased upon maturity but that pod length was not important factor in the identification of the def mutant.

In order to study whether seed fresh weight was a significant factor in pea seed abscission, we measured seed fresh weight at maximum size in each pod in all the four accessions used in this study. The most mature seed at pod identification P1.1 showed maximum seed fresh weight in all the four accessions whereas the youngest seeds (P10.1 in JI 116, P8.1 in JI 1184, P4.1 in JI 2822 and P3.1 in JI 3020) showed minimum seed fresh weight (Figure 1). Among accessions, seeds of dwarf types (JI 2822 and JI3020) were heavier and had slightly larger hilum areas than the tall types (JI 116 and JI1184), respectively (data not shown). The wild type pea seeds (JI 116 and JI 2822) were heavier than def mutant types (JI 3020 and JI 1184) seeds indicating that seed fresh weight may be an important factor in maturity and abscission event.

To study whether seed position has an effect on seed fresh weight, the seed fresh weight at the proximal and distal positions in the pod were measured. We observed a steady increase in seed fresh weight in both the proximal and distal locations in the pods of all accessions as they matured (Additional file 1: Table 1). In both proximal and distal location of seeds in JI 116 (wild type, tall), seed fresh weight increased in a similar way and there was no significant differences in seed fresh weight between proximal and distal locations. In addition, the interaction between proximal and distal seed locations was not significant in JI 1184, JI 2822 and JI 3020. Thus we established that the seed position did not have an effect on seed fresh weight.

\section{Seed growth and development}

For further growth and development analysis, the width of the funiculus (WFN), seed fresh weight (FW), seed width (SW), seed height $(\mathrm{SH})$ and their relationships were studied. A linear relationship between the WFN and the FW was observed in all four accessions (Figure 2). The best relationship was observed in wild type JI 2822 . The relationship between the WFN and the FW was described using the model WFN $=1.74+2.55 \mathrm{FW}$ which explained $57 \%$ of the variation in WFN. The relationship between the WFN and SW was best explained in the mutant JI 3020 using the model WFN $=1.74+0.326 \mathrm{SW}$ accounting 


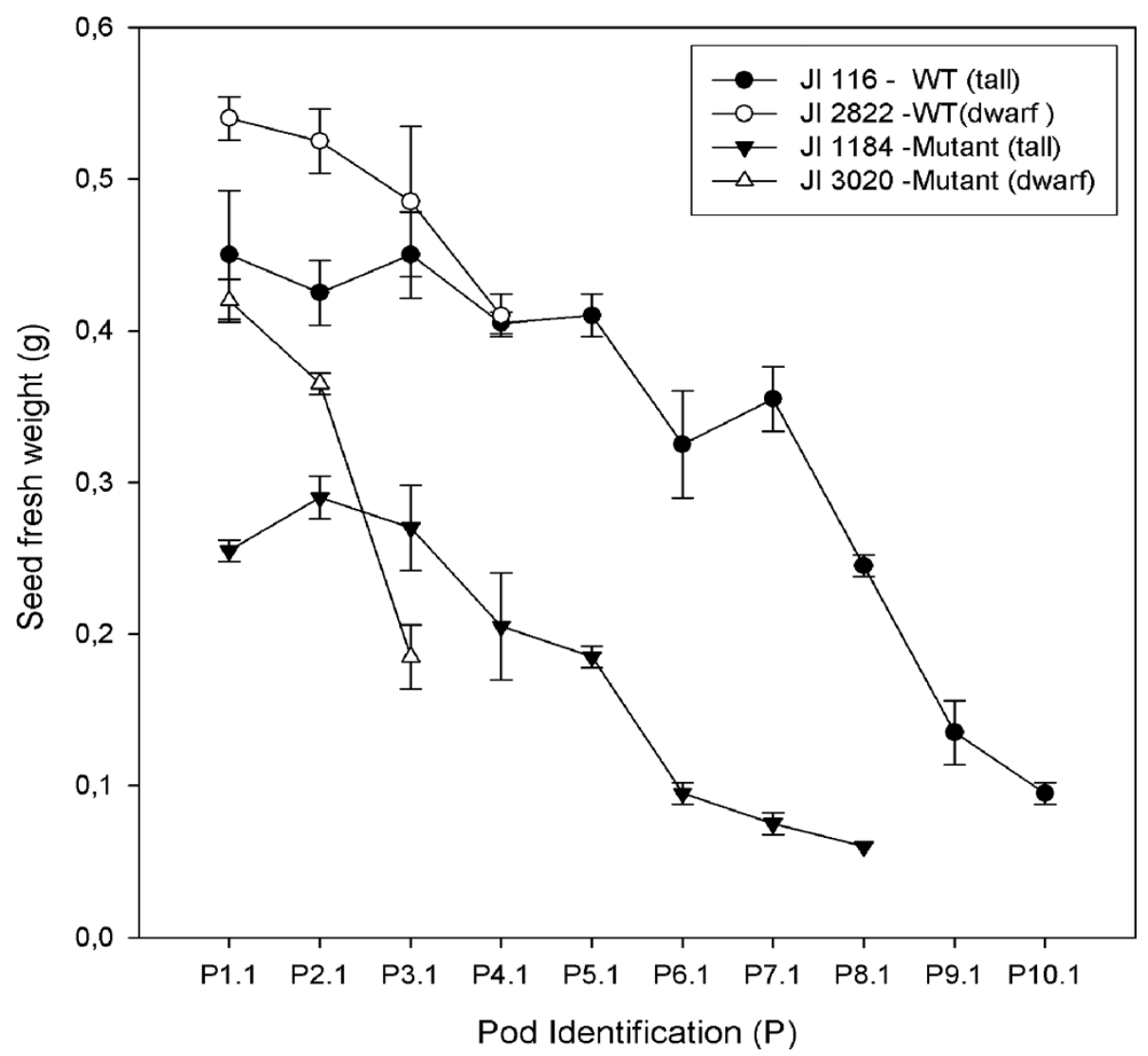

Figure 1 The relationship between seed fresh weight and pod age in the wild type and the def mutant $P$. sativum. $J 116$ is tall wild type. J 2822 is dwarf wild type. J 1184 is tall mutant and J 3020 is dwarf mutant. Seeds in the first (most mature) pod and close to pea stock are designated as P1.1. The youngest pod and close to the pea stock is designated as P10.1 for JI 116, P8.1 for JI 1184, P4.1 for JI 2822 and P3.1 for $\mathrm{Jl} 3020$.

for $53.2 \%$ of the variation (Figure 3 ). A lower correlation was observed in JI 116 with an $R^{2}$ value of $14.8 \%$. In addition, the best relationship between WFN and $\mathrm{SH}$ was found in mutant JI 3020 using the model WFN $=-0.114+$ $0.359 \mathrm{SH}$ (Figure 4). $R^{2}$ values for all the models describing the relationship between WFN and other predictors are presented in additional file 2: Table 2.

When FW together with SW were included in the model, wild type JI 2822 with $R^{2} 59.2 \%$ gave the best predictive ability with the regression equation WFN $=1.52+$ $1.89 \mathrm{FW}+0.0572 \mathrm{SW}$. A model with FW and $\mathrm{SH}$ included in the regression of JI 3020 gave an additional variance in

Table 1 Details of Pisum sativum accessions and their allelic status with respect to the Def locus

\begin{tabular}{lll}
\hline Accession & Name & Def allele \\
\hline$J 116$ & cV. Parvus & Def (wild type) \\
\hline$J 2822$ & RIL, research line & Def (wild type) \\
\hline$J 1184$ & Priekuskij-341-def & def (mutant) \\
\hline$J 3020$ & cV. Nord & def (mutant) \\
\hline
\end{tabular}

the WFN term with a $R^{2}$ value of $62.7 \%$ and the regression equation WFN $=1.15+1.39 \mathrm{FW}+0.204 \mathrm{SH}$. Again, JI 3020 gave the best predictive value when $\mathrm{SW}$ and $\mathrm{SH}$ were included in the model resulting in the regression equation WFN $=0.113+0.181 \mathrm{SW}+0.227 \mathrm{SH}$. WFN had an improved linear relationship when FW, SW and SH were all included in the model. In all the four accessions tested, def cultivars JI 3020 and JI 1184 with a $R^{2}$ value $65.3 \%$ and $55.1 \%$ respectively, explained much of the variation in WFN as compared to Def accession JI 2822 and JI 116 with $R^{2}$ values of $59.2 \%$ and $21.7 \%$ respectively. The regression equation explaining much of the variation in JI 3020 was $\mathrm{WFN}=0.155+0.052 \mathrm{FW}+0.176 \mathrm{SW}+$ $0.225 \mathrm{SH}, R^{2}=65.3 \%$. We included interaction terms, FW*SH, FW*SW and SW*SH in the model which comprised all the three predictors described. Additional variation was observed in the dwarf def accession JI 3020 when the interaction terms $\mathrm{FW}^{*} \mathrm{SH}, \mathrm{FW} * \mathrm{SW}$ and $\mathrm{SW} * \mathrm{SH}$ were included giving predictive $R^{2}$ values of $66.3 \%, 68.7 \%$ and $66.6 \%$ respectively. We also looked at the inclusion of the interaction term $\mathrm{FW}^{*} \mathrm{SH}^{*} \mathrm{SW}$ to explain variation in WFN. 


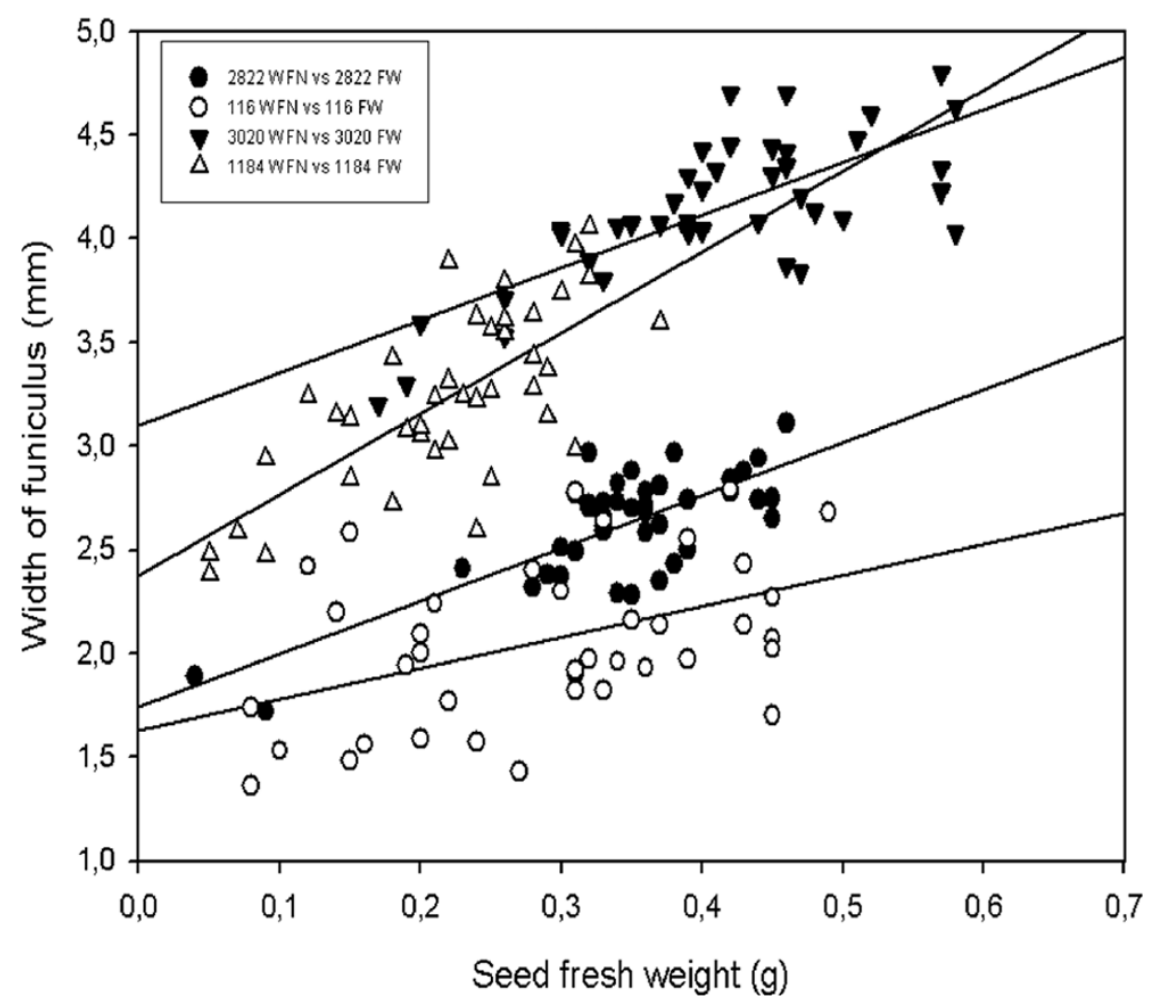

Figure 2 The relationship between seed fresh weight (FW) and width of funiculus (WFN) in the wild type and the def mutant Pisum sativum. Linear models were fitted to four data sets: Jl $116\left(Y=1.63+1.49 X_{i} R^{2}=19.6 \% ; P=0.000\right)$, J $2822\left(Y=1.74+2.55 X ; R^{2}=57.4 \% ; P=\right.$ 0.000), Jl $1184\left(Y=2.37+3.91 X_{i} R^{2}=51.7 \% ; P=0.000\right)$, Jl $3020\left(Y=3.10+2.54 X ; R^{2}=55.9 \% ; P=0.000\right)$.

We recorded a predictive value of $67.7 \%$ to explain the variation in the hilum size of the def JI 3020 as a result of the inclusion of an interaction term which included all the predictors in these study and these values were higher than those recorded for JI 2822, JI1184 and JI 116. The backward elimination method over pooled data from all four accessions was used to select and validate a model that best explained the relationship between WFN and the predictors as well as their interaction terms. Our results showed that variation of WFN of pea seeds was best associated with SH and SW $\left(R^{2}, 70.40\right.$; PRESS, 35, 6104).

Principal component analysis (PCA) applied to overall growth variation among two Def wild types and two def mutant types showed a $96 \%$ discrimination could be obtained using only two PCs (Figure 5). We observed differences among all four accessions. The PC1 grouped mutant with def loci, tall JI 1184 and dwarf JI 3020 separately from wild types JI 116 and JI 2822. In PC2, clusters were formed between tall (JI 116 and JI 1184) and dwarf phenotype (JI 2822 and JI 3020), thus grouping them together (Figure 5).

\section{Segregation analysis in two $F_{2}$ populations}

$F_{1}$ plants produced from crosses JI $2822 \times$ JI 1184 and JI $2822 \times$ JI 3020 were selfed to produce two different populations of $\mathrm{F}_{2}$. In population one (JI $2822 \times \mathrm{JI} 1184$ ), we observed the segregation pattern of the Def locus in two separate Mendelian ratios. When the ratio 3:1 was tested in population one, homozygous Def/Def seeds could not be distinguished phenotypically from heterozygous Defldef seeds and chi square $\left(\chi^{2}\right)$ analysis gave a value of $0.1212(P, 0.05)$ (Table 3$)$ hence we failed to reject the null hypothesis. When the ratio 1:2:1 was considered, $\mathrm{F}_{2}$ progeny, produced by crossing Def/def heterozygotes segregated into homozygous Def/Def, heterozygous Defldef and the homozygous def/def classes. However, $\chi^{2}$ value of 25.590 reveal that the observed ratios differ significantly from the expected ratios and therefore we rejected the null hypothesis. In the second population (JI $2822 \times \mathrm{JI}$ 3020), $F_{2}$ plants were produced from short $F_{1}$ heterozygous (phenotypically similar to Def/Def) plants (Table 4). The Mendelian ratios 3:1 revealed in chi square analysis that the $F_{2}$ progeny also segregated into two main classes, homozygous Def/Def and another homozygous line defl def. The $\chi^{2}$ values from the 3:1 test were 0.0666 . However when the ratio 1:2:1 was tested, three genotypic classes were segregated in the $\mathrm{F}_{2}$ seeds Def/Def: Defldef: def/def (1: $2: 1)$. The $\chi^{2}$ values were 56.1 and could reject the hypothesis. Therefore we accepted the null hypothesis in the $3: 1$ ratio. 


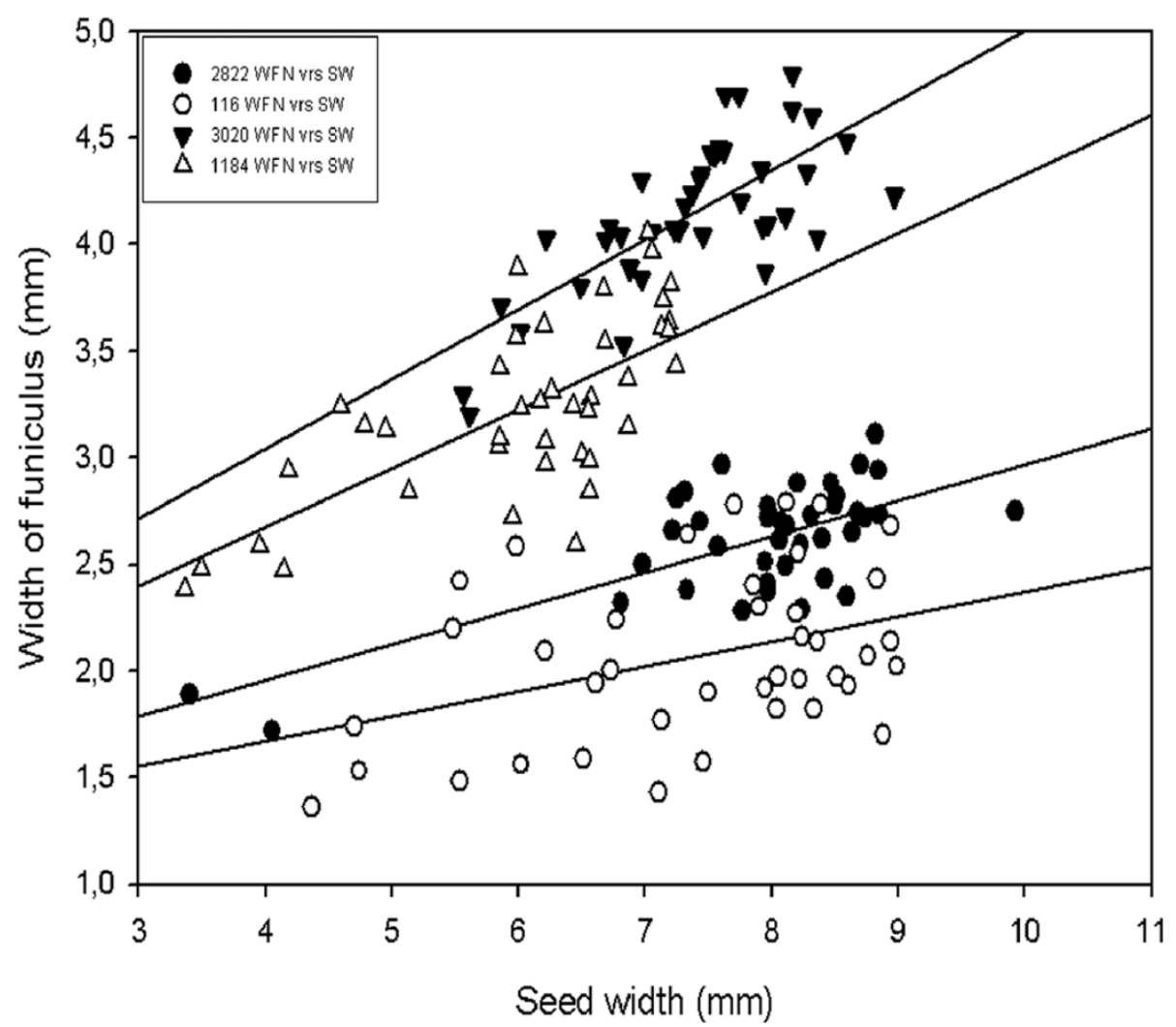

Figure 3 The relationship between seed width (SW) and width of funiculus (WFN) in the wild type and the def mutant Pisum sativum Linear models were fitted to four data sets: JI $116\left(Y=1.20+0.117 X ; R^{2}=14.8 \% ; P=0.001\right)$, Jl $2822\left(Y=1.28+0.169 X ; R^{2}=49.0 \% ; P=0.000\right)$, Jl $1184\left(Y=1.57+0.276 X ; R^{2}=48.2 \% ; P=0.000\right), J 3020\left(Y=1.74+0.326 X ; R^{2}=53.2 \% ; P=0.000\right)$.

Histological and developmental analysis of $\mathrm{F}_{3}$ segregants In order to confirm that the Def locus is monogenic, we crossed JI 2822 and JI 1184 which were then selfed to obtain the F2. The F2 generation was then grown to obtain seeds from the $F_{3}$. We selected three lines from the $\mathrm{F}_{3}$ population and they included heterozygote line 14 (Defldef), a dominant homozygous line 11 (Def/Def) and a recessive homozygous line 18 (def/def). Observations of histological data confirmed the 3:1 ratio (data not shown). However, we found an interesting aspect in the heterozygote line 14 that exhibited a partially formed palisade layer (Figure 6a). This partial palisade layer was observed in line 14 from 9 heterozygous lines from a total of 44 lines. Higher magnification of the partially formed palisade layer revealed the apparent absence of the counter palisade layer and yet the abscission process occurred nevertheless in the area where there is the partial counter palisade layer (Figure 6b). A homozygous dominant line 11 showed distinct double palisade layers and abscission development (Figure 6c and 6d) while a recessive (line 18) showed the lack of a palisade layer resulting in a non-abscission process (Figure 6e and 6f). The observed numbers of $F_{3}$ pod identification of the selected $\mathrm{F}_{3}$ segregants was an average of numbers of pod identification in parental JI 2822 and JI 1184. All the three lines showed a correlation between pod maturity and seed fresh weight with seed fresh weight generally increased upon pod maturity (Figure 6g).

We further analyzed the significance of the 3:1 ratio through structural examination of the second $F_{3}$ population produced from a cross between JI 2822 (dwarf wild type) and JI 3020 (dwarf mutant). Structural examinations of selected $\mathrm{F}_{3}$ segregants from this cross (heterozygous line 77, homozygous dominant line 1 and homozygous recessive line 33) were similar to parental. The double palisade layer was seen in heterozygous line 77 and the homozygous dominant line 1 (Figure $7 \mathrm{a}-\mathrm{d}$ ). However, the palisade layer in the young seed (P 3.1) of the heterozygous line 77, was less differentiated (Figure 7a and 7c) compared to the fully differentiated palisade layer in the young seed of homozygous dominant line 1 (Figure 7e and 7h). At higher magnification, the distinct separation of the palisade layers in the young heterozygous line 77 was less conspicuous (Figure 7c) compared to the young seed in the homozygous dominant line (Figure 7g). In the homozygous recessive line 33 , the abscission process was not 


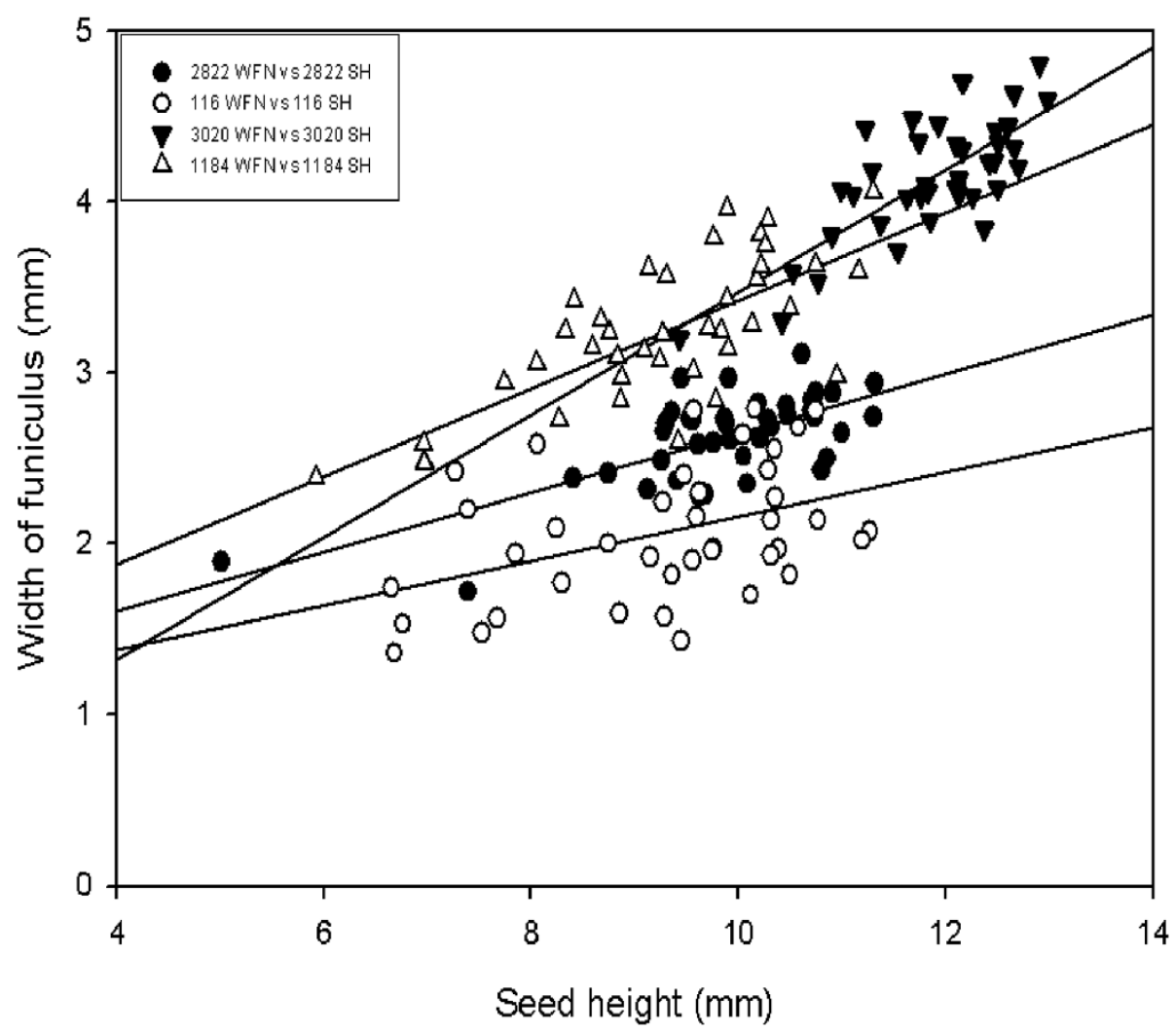

Figure 4 The relationship between seed height (SH) and width of funiculus (WFN) in the wild type and the def mutant Pisum sativum. Linear models were fitted to four data sets: Jl $116\left(Y=0.855+0.131 X_{i} R^{2}=17.9 \% ; P=0.051\right)$, J $2822\left(Y=0.909+0.173 X ; R^{2}=49.5 \% ; P=\right.$ 0.003), Jl $1184\left(Y=0.851+0.257 X ; R^{2}=53.5 \% ; P=0.024\right), J 3020\left(Y=-0.114+0.359 X_{i} R^{2}=56.6 \% ; P=0.852\right)$.

observed (Figure $7 \mathrm{i}$ and $7 \mathrm{j}$ ) and we observed that cells of a parenchymatous nature were highly irregular in shape (Figure $7 \mathrm{k}$ and $7 \mathrm{l}$ ). The $\mathrm{AZ}$ in the homozygous dominant line 1 was clearly defined with the cell separation event at an advance stage (Figure $7 \mathrm{f}$ and $7 \mathrm{~h}$ ). The seed fresh weight

Table 2 Changes in the pod length of wild type (JI 116 and J 2822) and def mutant (J 1184 and J 3020) peas (Pisum sativum) at various developmental growth stages

\begin{tabular}{lllll}
\hline Growth stage & $\begin{array}{l}\text { Mean cultivar pod length } \\
(\mathbf{m m})\end{array}$ & & \\
\cline { 2 - 5 } & Jl $\mathbf{1 1 6}$ & J $\mathbf{2 8 2 2}$ & J $\mathbf{1 1 8 4}$ & J $\mathbf{3 0 2 0}$ \\
\hline P8.1 & $55.7 \pm 4.6 \mathrm{~b}$ & & $34.0 \pm 9.4 \mathrm{a}$ & \\
\hline P7.1 & $59.3 \pm 4.7 \mathrm{ab}$ & & $40.3 \pm 7.7 \mathrm{a}$ & \\
\hline P6.1 & $61.0 \pm 2.1 \mathrm{ab}$ & & $49.3 \pm 3.5 \mathrm{a}$ & \\
\hline P5.1 & $64.73 \pm 2.6 \mathrm{ab}$ & & $52.0 \pm 1.2 \mathrm{ab}$ & \\
\hline P4.1 & $65.3 \pm 2.7 \mathrm{ab}$ & $46.7 \pm 3.3 \mathrm{~b}$ & $58.0 \pm 1.2 \mathrm{ab}$ & \\
\hline P3.1 & $68.3 \pm .5 \mathrm{a}$ & $53.0 \pm 3.6 \mathrm{ab}$ & $57.0 \pm 1.5 \mathrm{ab}$ & $59.7 \pm 4.4 \mathrm{a}$ \\
\hline P2.1 & $67.3 \pm 1.3 \mathrm{a}$ & $55.3 \pm 2.3 \mathrm{a}$ & $56.3 \pm 1.8 \mathrm{ab}$ & $67.7 \pm 3.4 \mathrm{~b}$ \\
\hline P1.1 & $67.7 \pm 1.4 \mathrm{a}$ & $55.3 \pm 2.7 \mathrm{a}$ & $59.7 \pm 0.35 \mathrm{~b}$ & $70.7 \pm 2.9 \mathrm{~b}$ \\
\hline
\end{tabular}

Mean \pm SE followed by different letters in the same column is significantly different at $P=0.05$ by the Tukey simultaneous comparison at pod identification P3.1 (younger stage) in heterozygous line 77 and homozygous recessive line 33 were lighter compared to homozygous dominant line 1 (Figure $7 \mathrm{~m}$ ). Similarly, seed fresh weight at pod identification P1.1 (mature stage) in homozygous dominant line 1 was heavier than the heterozygous line 77 and homozygous recessive line 33 and the homozygous dominant line 1 showed a more cell to cell separation in the AZ (Figure 7h).

\section{Discussion}

Abscission of seeds in wild type and def mutant pea The abscission of pea seeds can be defined as seed separation from the funicle [43]. This study focused on growth and development of seeds in two wild type lines and two def mutants lines. Sometimes abscission can be considered as the last step of organ developments and may be accompanied by senescence or aging [44]. The abscission process in wild type peas is correlated to seeds maturity since mature seeds easily abscised while young seeds fail to show any discernible abscission event. In previous work [8], a structural comparison between wild type pea and the def mutant showed different structural phenotype. The wild type underwent a 


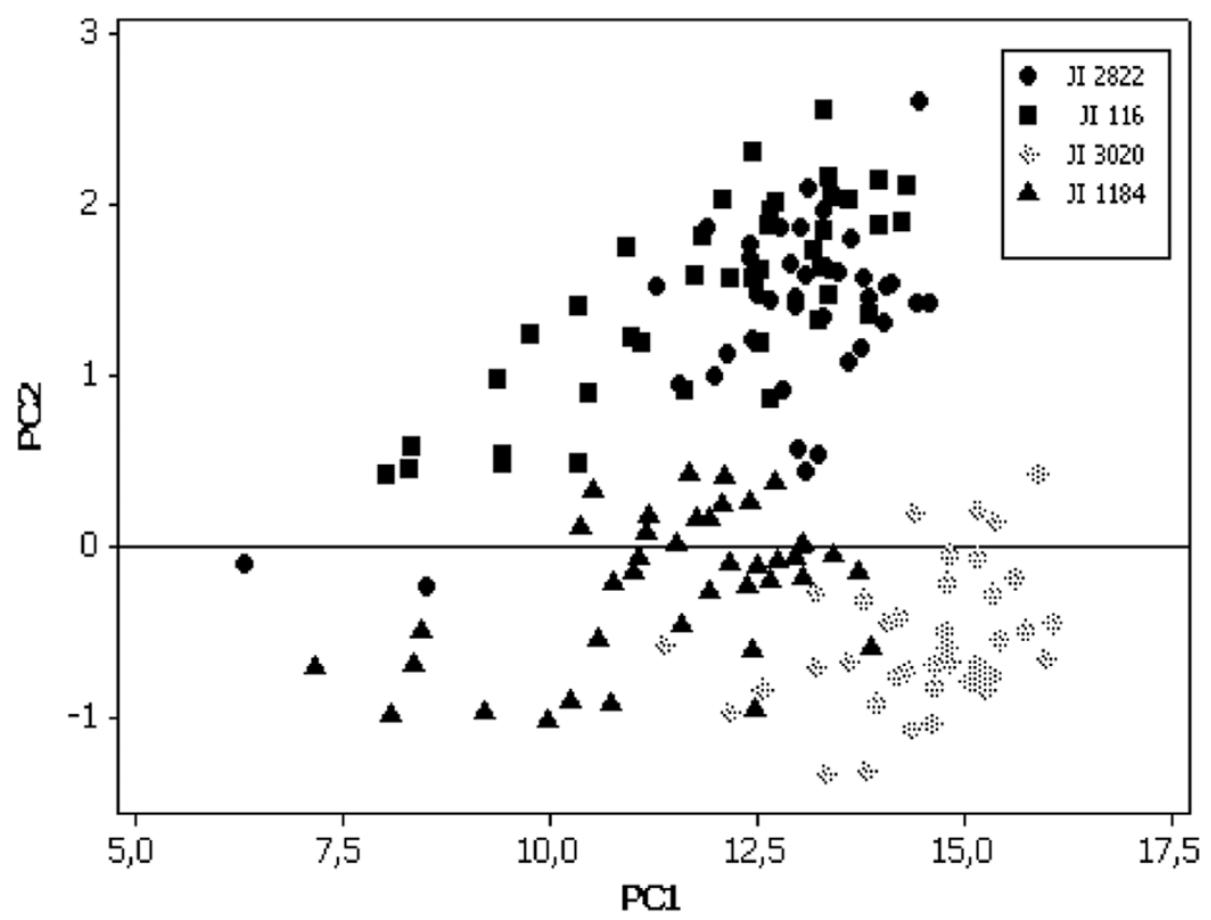

Figure 5 Principal component analysis (PCA) of the overall growth variation among two Def wild types and two def mutant peas.

normal abscission between the funicle and seed coat at maturity while def mutant exhibited a non-abscission event in the seeds. Therefore, the abscission event is highly related to seed maturity and the def locus is important in controlling the abscission event in pea seeds.

Our results showed that pod length increased and finally stabilized in mature pods. In all accessions, the initial increase in pod length is generally associated with initial seed filling process [45]. It is interesting to note that with the exception of tall mutant (JI 1184) the initial significant increase in pod length occurred at growth stage P7.1 whilst the in the tall mutant line it occurred at P5.1. This is not surprising since the time to anthesis was much longer in the tall JI 1184 than in the other accessions.

Seed fresh weight was measured to study the developmental growth pattern in seeds. In general, seed development in pea consisted of two growth phases and separated by two lag phases $[10,46]$. However, Carr and Skene [47], revealed a biphasic growth pattern separated by a single lag phase in French beans (Phaseolus vulgaris L). In our results obtained in the proximal and distal location of seeds in JI 116, an initial increase in seed fresh weight was recorded from P8.1 to P7.1 in the proximal end of pod whereas in the distal end, significant growth occurred from P8.1 to P6.1 (Table 2). The same trend was observed in JI 1184 at both proximal and distal

Table $3 F_{2}$ plants from selfing of the $F_{1}$ progeny resulting from the cross ل J $2822 \times 1184$

\begin{tabular}{|c|c|c|c|c|c|}
\hline & Genotype & Observed number $(0)$ & Expected number (E) & Difference (O-E) & $(O-E)^{2} / E$ \\
\hline \multirow[t]{4}{*}{ 3: 1} & Def/Def & 34 & 33 & 1 & 0.03030 \\
\hline & Def/def & - & - & - & - \\
\hline & def/def & 10 & 11 & -1 & 0.09090 \\
\hline & Total & 44 & 44 & 0 & $0.1212=\chi_{\text {calc }}{ }^{2}$ \\
\hline \multirow[t]{4}{*}{$1: 2: 1$} & Def/Def & 25 & 11 & 14 & 17.681 \\
\hline & Def/def & 9 & 22 & -13 & 7.681 \\
\hline & def/def & 10 & 11 & -1 & 0.0919 \\
\hline & $\overline{\text { Total }}$ & 44 & 44 & 0 & $25.590=\chi_{\text {calc }^{2}}$ \\
\hline
\end{tabular}

* 3:1 Observed values do not differ significantly from expected values at 1 degree of freedom and 0.05 levels of significance

*1: 2: 1 Observed values differ significantly from the expected value at 1 degree of freedom and 0.05 level of significance 
Table $4 F_{2}$ plants from selfing of the $F_{1}$ progeny resulting from the cross Jl $2822 \times \mathrm{Jl} 3020$

\begin{tabular}{|c|c|c|c|c|c|}
\hline & Genotype & Observed number (0) & Expected number (E) & Difference $(\mathrm{O}-\mathrm{E})$ & $(O-E)^{2} / E$ \\
\hline \multirow[t]{4}{*}{$3: 1$} & Def/Def & 59 & 60 & -1 & 0.01666 \\
\hline & Def/def & - & - & - & - \\
\hline & def/def & 21 & 20 & 1 & 0.05 \\
\hline & $\overline{\text { Total }}$ & 80 & 80 & 0 & $0.0666=\chi_{\text {calc }}{ }^{2}$ \\
\hline \multirow[t]{4}{*}{$1: 2: 1$} & Def/Def & 47 & 20 & 27 & 36.45 \\
\hline & Def/def & 12 & 40 & -28 & 19.60 \\
\hline & def/def & 21 & 20 & 1 & 0.05 \\
\hline & $\overline{\text { Total }}$ & 80 & 80 & 0 & $56.1=\chi_{\text {calc }^{2}}$ \\
\hline
\end{tabular}

* 3:1 Observed values do not differ significantly from expected value at 1 degree of freedom and 0.05 level of significance

* 1: 2: 1 Observed values differ significantly from the expected value at 1 degree of freedom and 0.05 level of significance

ends of the pod. In both dwarf wild type and def mutant types, initial growth rates were significant in both proximal and distal locations except for the distal part of JI 2822. The initial growth phase in all the accessions is due to cell division and associated with changes in the embryo, seed testa and endosperm [10]. Even though we observed a steady increase in seed fresh weight at the proximal and distal ends in tall wild type JI 116, rather slow growth was seen between P4.1 and P3.1 at the proximal end. At the distal end of JI 116, seed fresh weight changes were significant between developmental growth stage P4.1 and P2.1. This period of growth may represent overlaps in transition from the second growth phase to maturation phase. In the tall def mutant JI 1184, a steady increase after the initial seed growth was observed at both the proximal and distal locations of seeds in the pod until maximum seed fresh weight was reached at P2.1 at both proximal and distal seed locations. This steady increase in seed fresh weight until the maximum seed fresh weight was attained may represent a steady transition and attainment of seed maturation phase. In dwarf wild type JI 2822, maximum seed fresh was obtained at P2.1 at the proximal end and decreased at P1.1 indicating a maturation phase. However, maximum seed fresh weight at the distal end was $0.5 \mathrm{~g}$ and we found no lag phase. In dwarf def mutant type the growth pattern appear linear at both proximal positions. This linear accumulation of seed fresh weight in JI 3020 may suggest that there was the possibility of delayed termination of reserve accumulation as suggested by Chinnasamy and Bal [14] in grass pea seeds. At both proximal and distal ends, there was no appreciable increase in seed weight at P1.1 indicating the onset of the desiccation period where the seeds begin to dry. Generally, in both tall wild types and mutant types, there was no pronounced lag phase. This may be due to the choice of the developmental growth stages used in this study that did not cover this event. Seed maturation is an important phase in seed development and marks the termination of the growth of the embryo [48] prior to seed desiccation phase where the seed loses water and passes into a dormant stage [49]. In the present study seed maturation was observed in all lines to have occurred at P1.1. However, we observed that maturation occurred at the proximal end in JI 2822 at seed developmental stage (P2.1) followed by a well defined desiccation period at P1.1 where there was seed weight loss.

Generally there was a positive correlation between repressors (WFN) and all the predictors described in this study. Our results showed a better predictive value $\left(R^{2}\right.$, $57.4 \%$ ) and a positive correlation between WFN and FW in dwarf wild type (JI 2822) than tall wild type and mutant types. The observed relationship between WFN and FW obtained was consistent with the findings of Mawson et al. [50] who found that the size of the funiculus increases from an early developmental stage to a more advanced stage. WFN correlated positively with SW except for JI $116\left(R^{2}, 14.8 \%\right)$. The same pattern was observed when SH was regressed on WFN in def mutant lines than $D e f$ wild type lines. The general trend observed where mutants types exhibited better $R^{2}$ values than wild types (Additional file 2: Table 2) may be due to the fact that mutants, particularly JI 3020 (dwarf, mutant) have a much more swollen funiculus than in wild types (data not shown). A combination of two of the predictors as well as all three predictors and their interaction terms were included in the fitted models. The best predictive value $\left(R^{2}, 68.7 \%\right)$ was recorded in dwarf JI 3020 when the interaction term $\mathrm{FW}^{*} \mathrm{SW}$ was included in the fitted model as compared to where the interaction term $\mathrm{FW}^{*} \mathrm{SW}^{*} \mathrm{SH}$ was included. Thus it may be suggested there could be a relationship involving fresh weight and seed width. However, when data were pooled together and backward elimination of terms applied, the model excluded seed FW but included SH and SW in determining the best relationship between predictors and WFN. The results obtained from seed development and regression analysis involving all the four accession revealed differences. We further used PCA analysis to confirm and summarized the differences between the accessions. 


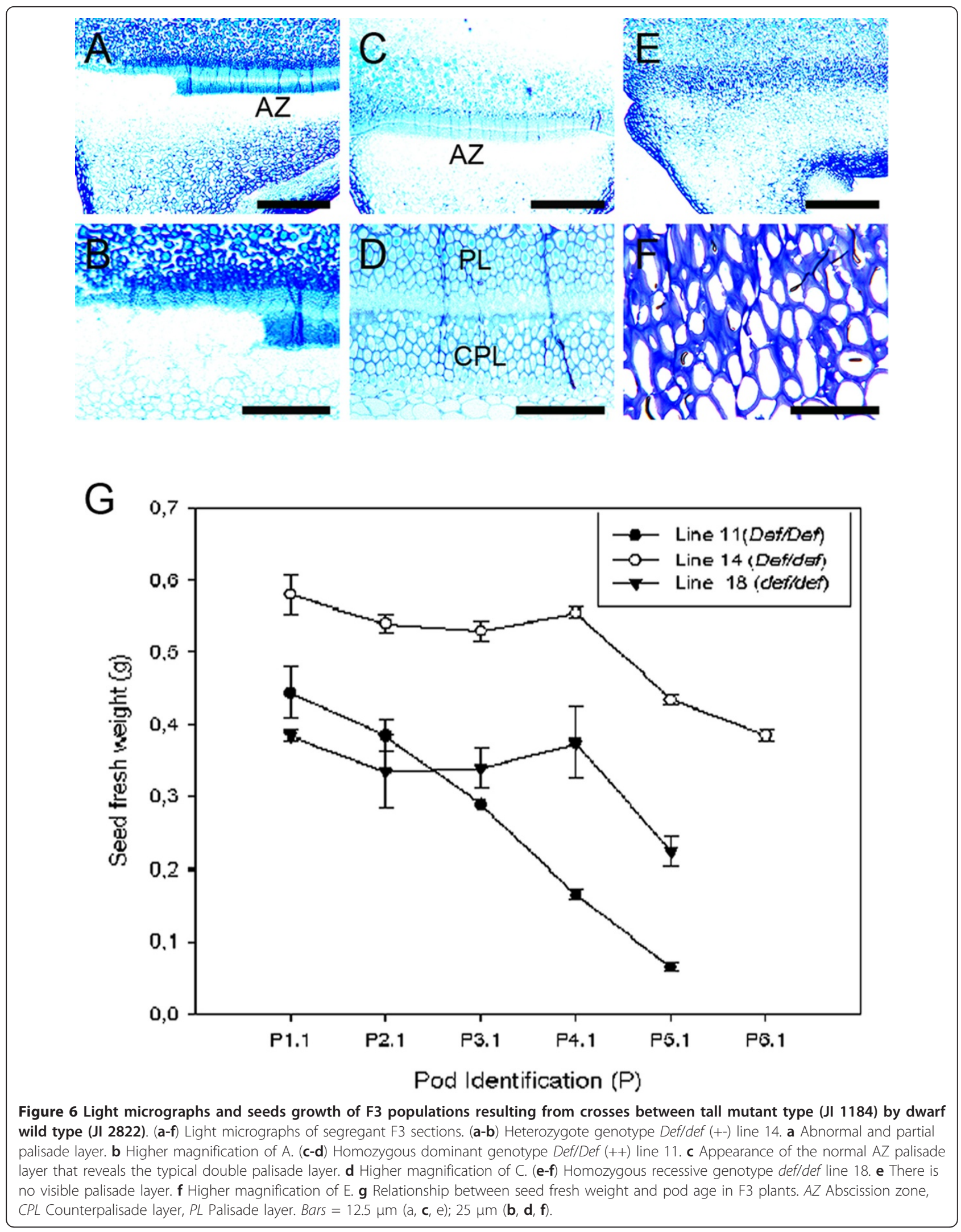



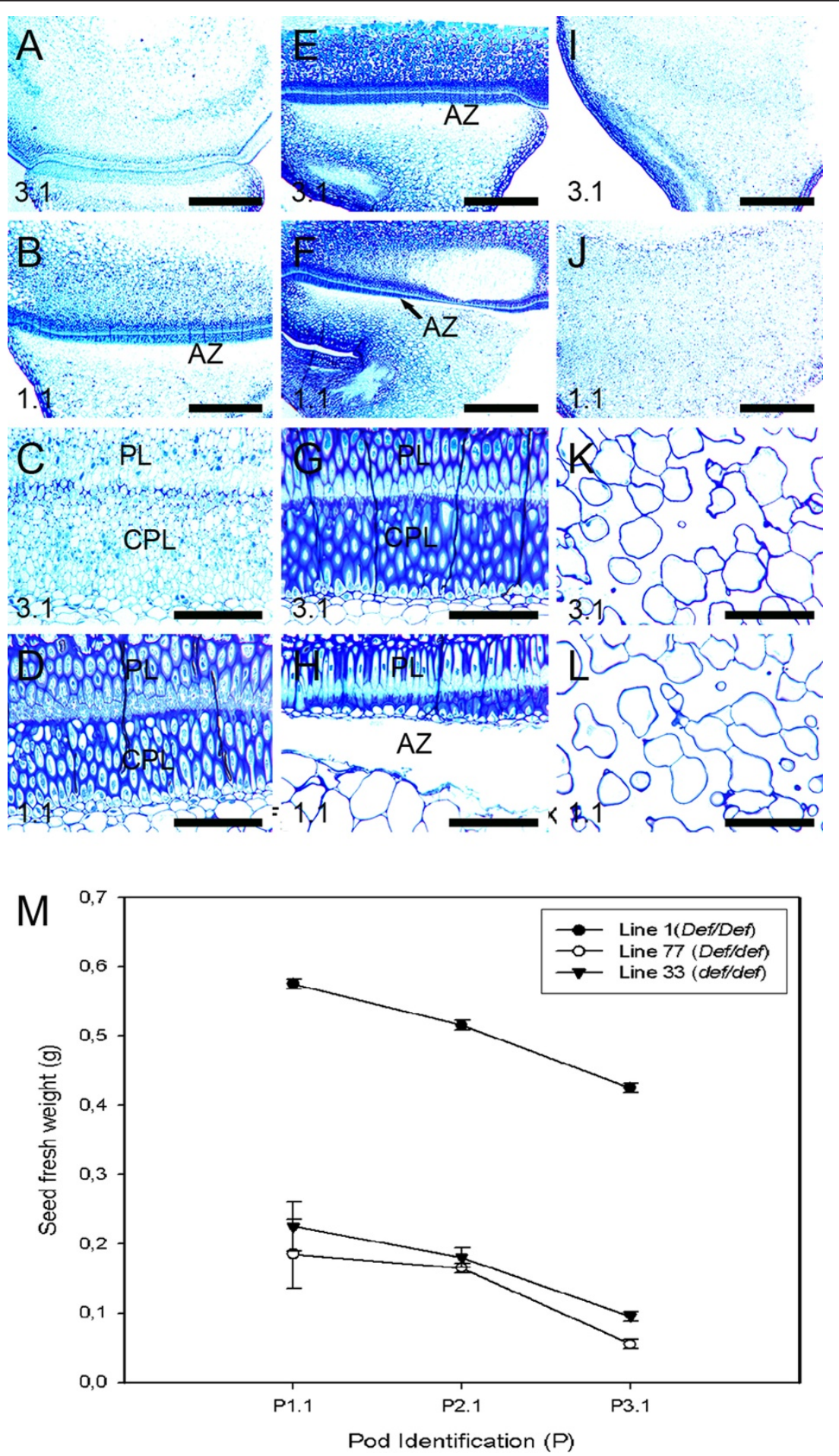

Figure 7 Light micrographs and seeds growth of F3 populations resulting from crosses between dwarf wild type (Jl 2822) and dwarf mutant pea (J 3020). (a-I) Light micrographs of segregant F3 sections. (a-d) Heterozygote genotype Def/def (+-) line 77. a Young seed of line 77 shows a less differentiated palisade layer. b Mature seed section of line 77 shows normal double palisade layer development. c-d Higher magnification of (a) and (b), respectively. (e-h) Homozygous dominant genotype Def/Def (++) line 1. e Young seed section of line 1. $\mathbf{f}$ Mature seed section of line 1. $\mathbf{g}$-h Higher magnification of (e) and (f), respectively. $\mathbf{i}-\mathbf{I}$ Homozygous recessive genotype line 33. (i) Young seed section of line 33 shows no distinct palisade layer. (j) Mature seed section of line 33. (k)-(I) Higher magnification of (i) and (j), respectively. (m) Relationship between seed fresh weight and pod age in F3 plants. AZ Abscission zone, CPL Counterpalisade layer, PL Palisade layer. Bars $=12.5 \mu \mathrm{m}(\mathbf{a}, \mathbf{b}, \mathbf{e}, \mathbf{f}$, $\mathbf{i}$, and $\mathbf{j}) ; 25 \mu \mathrm{m}(\mathbf{c}, \mathbf{d}, \mathbf{g}, \mathbf{h}, \mathbf{k}$, and $\mathbf{I})$. 
Segregation distortion may be explained as a deviation from expected ratios in a given phenotype or genotypic progenies within a segregating population [33]. In this work, we have used Pearson's chi square analysis to test and explain phenotypic ratios and quantify deviations in 3:1 and 1:2:1 Mendelian ratio when Def/Def wild type was crossed to defldef mutant. In the $\mathrm{F}_{1}$ progeny produced in the initial crosses, heterozygous Defldef obtained were not phenotypically different from the homozygous dominant (Def/Def) parents. Our results showed consistency with what would have been expected if the abscission event in pea wild type lines are under the control of a single dominant gene, Def [51]. Phenotypic segregation of $\mathrm{F}_{2}$ seeds showed that observed numbers obtained from a 1:2:1 ratio in the two populations tested was insignificant as revealed by $\chi^{2}$ values (25.590 and 56.1). These results agree with the work of Kloos et al. [52], who showed using chi square analysis that the inheritance of dark disk colour was determined by a single dominant gene. Chi square analysis have also been used to investigate excess or deficiency segregation distortion in $F_{2}$ populations of pea recombinant inbred populations [53]. Genetic analysis based on chi square analysis in two self pollinating pea plants revealed that embryo abortion was the cause of segregation distortion when the ratio 9:3:1 was tested [28]. Even though we did not observe large deviations from our 3:1 ratio, some of the factors that may be responsible for the deviations in the 1:2:1 ratios in the two populations, may include the presence of lethal genes that may be involved in the various stages of reproduction including sporogenesis, fertilization and seed development $[54,55]$.

\section{Structural analysis of $\mathrm{F}_{3}$ segregants}

We used the dwarf wild type JI 2822 in crosses with tall mutant types JI 1184 and dwarf mutant JI 3020 because JI 2822 has a black hilum surface which can be readily observed during the maturation phase. Black hilum is a good segregating morphological marker offering a clear visual reference to tissue differentiation at the macro level. The results of our genetic inheritance studies through cell structure analysis suggest that $D e f$ is determined by a onelocus diallelic system, indicating a single gene hypothesis. Structural analysis involving the dwarf wild type (JI 2822) and tall mutant (JI 1184) which were characterized genotypically as homozygous dominant lines (Def/Def), heterozygous lines (Def/def) and homozygous recessive lines (defl def). Phenotypic observation through structural analysis revealed that the heterozygous lines were similar to the homozygous dominant lines (data not shown). However, an aberrant or incomplete phenotype showing partial appearance of the palisade layer was observed in a heterozygous line from this cross (Figure $5 \mathrm{a}$ and $5 \mathrm{~d}$ ). A possible explanation for this aberrant phenotype may be that it arose through a spontaneous event as described for the inheritance of homostyles by Tamari [56]. Such abnormality may be attributed to a number of reasons including physiological, molecular and environmental factors [36]. The second $F_{3}$ population (JI $2822 \times$ JI 3020) confirmed the 3:1 segregation ratio in pea and no aberrant phenotypes among the heterozygous progeny was observed. The less differentiated palisade layer observed in the young seed of the heterozygous line 77 (Figure 6a), may possibly be due to the early developmental stage (Figure $6 \mathrm{~m}$ ). This is because the epidermal cells at that stage were made of cuboidal epidermal cells before the fully differentiated epidermal cells appear at stage P1.1 with a mature seed (Figure 6d) as described by Miller [57]. Generally, seed weight in $\mathrm{F}_{3}$ lines correlated with the formation of an AZ. Mature seeds had a clearer AZ than young seeds in Def wild type. Generally, seed weight correlated with the maturity of the pod on the pea plant. The similar size of the $F_{3}$ progenies to that of parental may suggest the influence of a maternal effect in seed maturation in the $\mathrm{F}_{3}$ progenies due to access to resources from the maternal seed [58]. The interactive influence of maternal photoperiod and temperature has also been hypothesized to control the molecular expression in progenies of Norway spruce [59]. However, it has also been suggested that final seed weight may be determined by genetic, environment and frequently significant genotype $\times$ environment interactions [60].

\section{Conclusions}

The palisade and counter-palisade layers, by default is the structure that delimits the seed coat and the funicle in the wild type pea carrying the Def locus and is thus the location for where the abscission of the funicle from the seed occurs. This layer was conspicuously absent in the mutant cultivars that carry the recessive def allele. In addition, we confirm earlier findings through anatomical analysis that the inheritance of the AZ defined by Def allele was controlled by the Def locus [51]. We observed the presence of a partially formed palisade layer and a less differentiated palisade layers in young seeds in two $F_{3}$ populations. However, the number of seeds with such phenotypes were small and insignificant compared to the significant 3:1 segregation ratio. This study investigated the inheritance of the presence or absence of the Def allele, controlling phenotypes where there is $\mathrm{AZ}$ or an ALZ formation in wild type and mutant lines respectively. The single major gene (Def) controlling this phenotype was identified by Mendelian genetic analysis, confirming earlier findings on the def allele [51].

\section{Methods}

\section{Plant materials}

The four lines of pea (Pisum sativum L.) seeds JI 116, JI 2822, JI 1184 and JI 3020 used in this study were selected on the basis of the presence of specific alleles at the Def 
locus, which control the detachment of the seed from the funicle (Table 1). JI 1184 originates from Rozenthal's collection from Russia where the def mutation was first identified and isolated and is an early line selected as carrying the def allele. It has been used for agronomic studies and is a sister line to the type line for def mutant allele. JI 3020 is a registered cultivar from the Netherlands that incorporates the same mutant def allele. In the absence of near-isogenic lines for the Def alleles, two well characterized lines (JI 116 and JI 2822) that matched the gross plant habit of the mutant lines were selected. Both these lines are well characterized genetically and were selected for use in genetic analysis of heterozygous Def/ def seeds that are the subject of further study of this locus.

Seeds corresponding to each line were sown in pots with fertilised peat (Floralux, Nittedal Torvindustrier, Norway) and grown under greenhouse conditions at $22^{\circ}$ $\mathrm{C}$ and $16 / 8 \mathrm{~h}$ photoperiod with a photon flux of 110 $\mu \mathrm{mol} \mathrm{m} \mathrm{m}^{-2} \mathrm{~s}^{-1}$ (400-700 nm Photosynthetic Active Radiation (PAR)) and a day length extending light provided from incandescent lamps (OSRAM, Germany).

Seeds from two populations were produced from crosses JI $3020 \times$ JI 2822 (population one) and JI $1184 \times$ JI 2822 (population two). The F1 from the two populations were self-crossed to produce $\mathrm{F}_{2}$ plants.

\section{Definition of pod identification and measurement of growth}

The development of the abscission process was shown to correlate with maturity of seeds, by measuring seed fresh weight at each pod identification stage. Seeds in the first (most mature) pod and close to pea stock are designated as P1.1. The youngest pod and close to the pea stock is designated as P10.1 for JI 116, P8.1 for JI 1184, P4.1 for JI 2822 and P3.1 for JI 3020. This system was also applied to seeds in $F_{3}$ populations. Seed fresh weight at corresponding pod identification stages were measured in $\mathrm{F}_{3}$ populations

Pod length, proximal and distal seed fresh weights corresponding to each developmental growth stage of the four accessions (JI 116, JI 1184, JI 2822 and JI 3020) were measured. Forty seeds per accession were harvested after maturity in all the four accession. Seeds were randomly selected through the entire developmental series. The width of the funiculus on the seed (WFN), fresh weights $(\mathrm{FW})$, seed width (SW) and seed height $(\mathrm{SH})$ were measured and then analysed statistically.

\section{Statistical analysis}

Means and standard deviations of pod length and seed fresh weight were computed using the Tukey simultaneous comparison test (Minitab version 15). The relationships between WFN and FW, SW and SH were evaluated by fitting regression models with Multiple Linear Regression (MLR) analysis procedure of Minitab (Version 15). The internal validity of the models was tested by coefficient of determination $\left(R^{2}\right)$. Model validations of a pooled data of all the accessions were carried out using the stepwise elimination option (Minitab version 15). We also used Principal Components Analysis (PCA) [61], to find clusters between pea Def wild type and def mutant lines. In addition, pearson's goodness of fit test was used to study two segregations ratios (3:1 and 1:2:1) to interpret phenotypic ratios and quantify the various deviations expected by chance as described by Halliburton [62].

\section{$F_{3}$ plant material}

Segregation patterns in the inheritance of the Def locus were studied in two $\mathrm{F}_{3}$ populations produced by crossing (Table 5). Selected seeds lines from two $F_{3}$ populations were produced from crosses between parental JI $2822 \times$ JI 1184 (population one) and JI $2822 \times$ JI 3020 (population two). The $F_{1}$ from the two populations were selfed to produce $F_{2}$ plants. $F_{2}$ populations were grown under same conditions described above to produce $F_{3}$ seeds in two populations and then used for structural examination and seed growth measurement.

\section{Plant tissue preparation and examination}

For structural analysis, seeds of all lines were embedded in LR White resin (London Resin Company, England) as mentioned in Ayeh et al. [8] Briefly, seeds were cut into $2 \mathrm{~mm}$ thick and immediately fixed in $1 \%$ formaldehyde, $0.025 \%$ glutaraldehyde, $0.1 \%(v / v)$ Tween 20 in $0.01 \mathrm{M}$ sodium phosphate buffer, $\mathrm{pH} 7.2$ and vacuum infiltrated

Table 5 Genetic characterization of two populations of F3 lines used for structural analysis

\begin{tabular}{|c|c|c|c|}
\hline Cross & Phenotypic description & F3 population (Line) & Presence/absence of Def locus in F3 lines \\
\hline \multirow[t]{3}{*}{$\|2822 \times\|$} & Dwarf wild type $\times$ Tall mutant & 1 & ++ \\
\hline & & 77 & +- \\
\hline & & 33 & -- \\
\hline \multirow[t]{3}{*}{$\mathrm{J} 2822 \times 3020$} & Dwarf wild type $\times$ Dwarf mutant & 11 & ++ \\
\hline & & 14 & +- \\
\hline & & 18 & -- \\
\hline
\end{tabular}

+ + Homozygous dominant (Def/Def); + - Heterozygous dominant (Def/def); - - Homozygous recessive (def/def) 
for $1 \mathrm{~h}$. The fixed tissues were placed at $4^{\circ} \mathrm{C}$ overnight and then dehydrated in a graded ethanol series. After infiltration, the specimens were embedded in LR White and polymerised at $50^{\circ} \mathrm{C}$ for $24 \mathrm{~h}$. For histological staining, sectioned materials ( $1 \mu \mathrm{m}$ thick) were stained with toluidine blue O (Sigma, USA) and mounted in Depex (BDH, USA). Sections were examined using a Leica brightfield microscope (Leica, Germany).

\section{Additional material}

\section{Additional file 1:}

Additional file 2 :

\section{Acknowledgements}

Kwadwo O. Ayeh wishes thank to The Norwegian Arabidopsis Research Centre (NARC) at The Norwegian University of Life Sciences (UMB) and Prof. Odd Arne Rognli for financial contribution. The authors would also like to thank Hilde R. Kolstad, Kari Boger and Tone Melby for technical support.

\section{Author details}

${ }^{1}$ The Biotechnology and Nuclear Agriculture Research Institute (BNARI), Ghana Atomic Energy Commission (GAEC), P.O.Box Lg. 80, Legon-Accra, Ghana. ${ }^{2}$ Department of Plant and Environmental Sciences, Norwegian University of Life Sciences, P.O. BOX 5003, 1432 Aas, Norway. ${ }^{3}$ Department of Crops Genetics, John Innes Centre, Norwich Research Park, Colney Lane, NR4 7UH Norwich, UK.

\section{Authors' contributions}

$\mathrm{KOA}$ contributed to the growing of the plants, harvested materials, carried out the experimental examination and drafted the manuscript. YKL participated in designing the experiments, structural analysis and the drafting of the manuscript. MA contributed with plant material, the general idea of the study and participated in revision of the manuscript. AKHE participated in the general idea of the study, the design of the experiments and contributed to the writing and revision of the paper. All authors have read and approved the final manuscript.

\section{Competing interests}

The authors declare that they have no competing interests.

Received: 1 August 2011 Accepted: 11 November 2011 Published: 11 November 2011

\section{References}

1. Gandzelo NG, Khangildin W: Investigation of new mutant genes in the pea .4. Diallele analysis of seed productivity of the nonshattering pea cultivars containing def gene. Genetika 1989, 25:659-665.

2. Khangildin WV: Investigation of new mutant genes in the pea .1. Genes def, le, Im, fn, fna and their influence on seed productivity. Genetika 1981, 17:2004-2012.

3. Khangildin WV, Nuriakhmetov DF: Identification of new mutant genes in the pea .3. The effect of def gene stipulating the nonshattering on combining ability, seed productivity and homeostasis in the system of tester crosses. Genetika 1988, 24:298-305.

4. Rozental AJ: Novaya forma gorokha. Bobowyje i ziernobobowyje kultury Moskwa 1966, 73-75.

5. Swiecicki W, Wolko B: Locus for the gene def (development funiculus). Pisum Newslett 1990, 22:67-68.

6. Weeden NF, Ellis THN, Timmermann-Vaughan GM, Swiecicki WK, Rosov SM, Berdnikov VA: A consensus linkage map for Pisum sativum. Pisum Genet 1998, 30:1-4

7. Weeden NF, Wolko B: Genetic maps. Genetic maps O'brien SJ: Cold spring harbor; 1990, 6106-6112.
8. Ayeh K, Lee $Y$, Ambrose M, Hvoslef-Eide A: Characterization and structural analysis of wild type and a non-abscission mutant at the development funiculus (Def) locus in Pisum sativum L. BMC Plant Biol 2009, 9:76.

9. von Stackelberg ML, Lindemann S, Menke M, Riesselmann S, Jacobsen HJ: Identification of AFLP and STS markers closely linked to the def locus in pea. Theor Appl Genet 2003, 106:1293-1299.

10. Wang T, Hedley CL: Genetic and developmental analysis of the seed. In Peas: Genetics, molecular biology and biochemistry. Edited by: Casey R, Davies DR. Cambridge, UK: CAB Intl; 1993:83-120.

11. Lemontey C, Mousset-Declas C, Munier-Jolain N, Boutin JP: Maternal genotype influences pea seed size by controlling both mitotic activity during early embryogenesis and final endoreduplication level/cotyledon cell size in mature seed. J Exp Bot 2000, 51:167-175.

12. Brocard-Gifford IM, Lynch TJ, Finkelstein RR: Regulatory networks in seeds integrating developmental, abscisic acid, sugar, and light signaling. Plant Physiol 2003, 131:78-92

13. Eeuwens CJ, Schwabe WW: Seed and pod wall development in Pisum sativum, $\mathrm{L}$ in relation to extracted and applied hormones. J Exp Bot 1975, 26:1-14.

14. Chinnasamy G, Bal AK: The pattern of seed development and maturation in beach pea (Lathyrus maritimus). Can J Bot 2003, 81:531-540.

15. Nakamura RR: Seed abortion and seed size variation within fruits of Phaseolus vulgaris pollen donor and resource limitation effects. Am J Bot 1988, 75:1003-1010.

16. Rocha OJ, Stephenson AG: Effect of ovule position on seed production, seed weight, and progeny performance in Phaseolus coccineus $\mathrm{L}$ (Leguminosae). Am J Bot 1990, 77:1320-1329.

17. Bond WJ, Honig M, Maze KE: Seed size and seedling emergence: an allometric relationship and some ecological implications. Oecologia 1999, 120:132-136.

18. Leishman MR, Westoby M, Jurado $E$ : Correlates of seed size variation - a comparison among 5 temperate floras. J Ecol 1995, 83:517-529.

19. Jurado $E$, Westoby M: Seedling growth in relation to seed size among species of Arid australia. J Ecol 1992, 80:407-416.

20. Koelewijn HP, Van Damme JMM: Effects of seed size, inbreeding and maternal sex on offspring fitness in gynodioecious Plantago coronopus. $J$ Ecol 2005, 93:373-383.

21. Jaradat AA, Rinke JL: Flowering, capsule and seed characteristics in Cuphea. Euphytica 2008, 161:447-459.

22. Hardham AR: Structural aspects of pathways of nutrient flow to developing embryo and cotyledons of Pisum sativum L. Austra J Bot 1976, 24:711-721.

23. Kumar S, Gill BS, Faris JD: Identification and characterization of segregation distortion loci along chromosome 5B in tetraploid wheat. Mol Gen Genom 2007, 278:187-196.

24. Stadler BMR: Heteroclinic cycles and segregation distortion. J Theor Biol 1996, 183:363-379.

25. Wang CM, Zhu CS, Zhai HQ, Wan JM: Mapping segregation distortion loci and quantitative trait loci for spikelet sterility in rice (Oryza sativa L.). Genet Res 2005, 86:97-106.

26. Lyttle TW: Segregation distorters. Annu Rev Gen 1991, 25:511-557

27. Taylor DR, Ingvarsson PK: Common features of segregation distortion in plants and animals. Genetica 2003, 117:27-35.

28. De Martino T, Errico A, Lassandro A, Conicella C: Distorted segregation resulting from pea chromosome reconstructions with alien segments from Pisum fulvum. J Hered 2000, 91:322-325.

29. Paredes $O M$, Gepts P: Segregation and recombination in inter gene pool crosses of Phaseolus vulgaris L. J Hered 1995, 86:98-106.

30. Lambrides CJ, Godwin ID, Lawn RJ, Imrie BC: Segregation distortion for seed testa color in mungbean (Vigna radiata L. Wilcek). J Hered 2004, 95:532-535.

31. Devaux P, Kilian A, Kleinhofs A: Comparative mapping of the barley genome with male and female recombination derived, doubled haploid populations. Mol Gen Genet 1995, 249:600-608.

32. Zivy M, Devaux P, Blaisonneau J, Jean R, Thiellement H: Segregation distortion and linkage studies in microspore-derived double haploid lines of Hordeum vulgare L. Theor Appl Genet 1992, 83:919-924.

33. Dufour P, Johnsson C, Antoine-Michard S, Cheng R, Murigneux A, Beckert M: Segregation distortion at marker loci: Variation during microspore embryogenesis in maize. Theor App/ Genet 2001, 102:993-1001. 
34. Lu H, Romero-Severson J, Bernardo R: Chromosomal regions associated with segregation distortion in maize. Theor Appl Genet 2002, 105:622-628.

35. Harushima Y, Kurata N, Yano M, Nagamura Y, Sasaki T, Minobe Y, Nakagahra M: Detection of segregation distortions in an Indica jjaponica rice cross using a high resolution molecular map. Theor Appl Genet 1996, 92:145-150.

36. Xu Y, Zhu L, Xiao J, Huang N, McCouch SR: Chromosomal regions associated with segregation distortion of molecular markers in F-2, backcross, doubled haploid, and recombinant inbred populations in rice (Oryza sativa L). Mol Gen Genet 1997, 253:535-545.

37. Faris JD, Laddomada B, Gill BS: Molecular mapping of segregation distortion loci in Aegilops tauschii. Genetics 1998, 149:319-327.

38. Peng J, Korol AB, Fahima T, Roder MS, Ronin YI, Li YC, Nevo E: Molecular genetic maps in wild emmer wheat, Triticum dicoccoides: genome wide coverage, massive negative interference, and putative quasi linkage. Genom Res 2000, 10:1509-1531.

39. Zhang HB, Dvorak J: Characterization and distribution of an interspersed repeated nucleotide sequence from Lophopyrum elongatum and mapping of a segregation distortion factor with it. Genome 1990, 33:927-936.

40. Xiao J, Wang X, Hu Z, Tang Z, Xu C: Multivariate segregation analysis for quantitative traits in line crosses. Heredity 2007, 98:427-435.

41. Wang J, Podlich DW, Cooper M, DeLacy $\mid H$ : Power of the joint segregation analysis method for testing mixed major gene and polygene inheritance models of quantitative traits. Theor Appl Genet 2001, 103:804-816.

42. Zeng W, Li BL: Simple tests for detecting segregation of major genes with phenotypic data from a diallel mating. Forest Sci 2003, 49:268-278.

43. Gonzalez-Carranza ZH, Lozoya-Gloria E, Roberts JA: Recent developments in abscission: Shedding light on the shedding process. Trends Plant Sci 1998, 1:10-14

44. Farage-Barhom S, Burd S, Sonego L, Perl-Treves R, Lers A: Expression analysis of the BFN1 nuclease gene promoter during senescence, abscission, and programmed cell death-related processes. J Exp Bot 2008, 59:3247-3258.

45. Ney $B$, Duthion C, Fontaine $\mathrm{E}$ : Timing of reproductive abortions in relation to cell division, water content, and growth of pea seeds. Crop Sci 1993, 33:267-270.

46. Hedley $\mathrm{CL}$, Ambrose MJ: An analysis of seed development in Pisum sativum L. Ann Bot 1980, 46:89-105.

47. Carr DJ, Skene KGM: Diauxic growth curves of seeds, with special reference to french beans (Phaseolus vulgaris L.). Austra J Biolog Sci 1961, 14:1-12.

48. Gutierrez L, Van Wuytswinkel O, Castelain M, Bellini C: Combined networks regulating seed maturation. Trends Plant Sci 2007, 12:294-300.

49. Kermode AR: Regulatory mechanisms involved in the transition from seed development to germination. Crit Rev Plant Sci 1990, 9:155-195.

50. Mawson BT, Steghaus AK, Yeung EC: Structural development and respiratory activity of the funiculus during bean seed (Phaseolus vulgaris L) maturation. Ann Bot 1994, 74:587-594.

51. Khangildin VK, Khangildin V: Nekotorye rezultaty geneticheskikh issledovanijs gorokhom. Voprosy genetiki i sjelekcji sjelskohozjajstwienych rastieniejTrudy Bashkirskogo Nauchno-Issledovatelsta 1969, 40-61.

52. Kloos WE, George CG, Sorge LK: Dark disk color in the flower of Gerbera hybrida is determined by a dominant gene, dc. Hortscience 2005, 40:1992-1994.

53. Knox MR, Ellis THN: Excess heterozygosity contributes to genetic map expansion in pea recombinant inbred populations. Genetics 2002, 162:861-873.

54. Cheng R, Kleinhofs A, Ukai Y: Method for mapping a partial lethal factor locus on a molecular marker linkage map of a backcross and doubled haploid population. Theor App/ Genet 1998, 97:293-298.

55. Hedrick PW, Muona O: Linkage of viability genes to marker loci in selfing organisms. Heredity 1990, 64:67-72.

56. Tamari F, Khosravi D, Hilliker AJ, Shore JS: Inheritance of spontaneous mutant homostyles in Turnera subulata $\mathrm{x}$ krapovickasii and in autotetraploid T. scabra (Turneraceae). Heredity 2005, 94:207-216.

57. Miller SS, Bowman LAA, Gijzen M, Miki BLA: Early development of the seed coat of soybean (Glycine max). Ann Bot 1999, 84:297-304.

58. Watson MA, Casper BB: Morphogenetic constraints on patterns of carbon distribution in plants. Annu Rev Ecol Syst 1984, 15:233-258.
59. Johnsen $\varnothing$, Dahlen OG, Østreng G, Skrøppa T: Daylength and temperature during seed production interactively affect adaptive performance of Picea abies progenies. New Phytol 2005, 168:589-596.

60. Stringi L, Amato G, Gristina L, D G: Correlations and path coefficients among yield components in Vicia faba L. equina and minor in a semiarid environment. Proceedings in 1st European Conference on Grain Legumes 1992, 297-298.

61. Hubert M, Engelen S: Fast cross-validation of high breakdown resampling methods for PCA. Compu Statis Data Anal 2007, 51:5013-5024.

62. Halliburton R: Introduction to population genetics. Pearson Education, Inc, Upper saddle, river, NJ 07458 2004, 69-89.

doi:10.1186/1756-0500-4-489

Cite this article as: Ayeh et al:: Growth, seed development and genetic analysis in wild type and Def mutant of Pisum sativum L. BMC Research Notes 2011 4:489.

\section{Submit your next manuscript to BioMed Central and take full advantage of:}

- Convenient online submission

- Thorough peer review

- No space constraints or color figure charges

- Immediate publication on acceptance

- Inclusion in PubMed, CAS, Scopus and Google Scholar

- Research which is freely available for redistribution

Submit your manuscript at www.biomedcentral.com/submit
C Biomed Central 